\title{
Massive export of diazotrophs across the South Pacific tropical Ocean
}

\author{
Sophie Bonnet*, Mar Benavides, Frédéric A.C. Le Moigne, Mercedes Camps, Antoine Torremocha, \\ Olivier Grosso, Céline Dimier, Dina Spungin, Ilana Berman-Frank, Laurence Garczarek, Francisco M. \\ Cornejo-Castillo \\ *corresponding author \\ Sophie.bonnet@mio.osupytheas.fr
}

\begin{abstract}
Diazotrophs are widespread microorganisms that alleviate nitrogen limitation in $60 \%$ of our oceans, regulating marine productivity. Yet, their contribution to organic matter export has not been quantified, making an assessment of their impact on the biological carbon pump impossible. Here, we demonstrate that cyanobacterial and non-cyanobacterial diazotrophs are massively exported down to 1000 m-depth in the western subtropical South Pacific Ocean (WTSP), accounting for up to $52-100 \%$ of the total particulate nitrogen export fluxes. We further demonstrate that small size unicellular diazotrophs (UCYN, 1-8 $\mu \mathrm{m})$ are exported more efficiently than filamentous diazotrophs $(>100-1000$ $\mu \mathrm{m})$ under the form of large $(>50 \mu \mathrm{m})$ aggregates linked by an extracellular organic matrix. Beyond the WTSP, our data are supported by analysis of the Tara Oceans metagenomes collected in other ocean basins, showing that diazotrophs are systematically detected in mesopelagic waters when present at the surface. We thus conclude that diazotrophs are key players in carbon sequestration in the ocean and need to be considered in future studies to improve the accuracy of current regional and global estimates of export.
\end{abstract}

\section{Introduction}

Nitrogen $(\mathrm{N})$ availability limits primary productivity throughout much of the surface low-latitude ocean 1 . In such nitrogen $(\mathrm{N})$-limited waters, microbial dinitrogen $\left(\mathrm{N}_{2}\right)$ fixation by diazotrophic plankton provides the major source of new $\mathrm{N}$ to surface waters ${ }^{2}$ that maintains the ocean fertility and, on appropriate timescales, equates export production to the deep ocean ${ }^{3}$. However, the fate of this production remains obscure ${ }^{4}$. No consensus as whether it is exported to the deep ocean or stimulates remineralization in surface waters currently exists. An increasing number of studies have shown that diazotroph-derived $\mathrm{N}$ is quickly translocated to non-diazotrophic plankton such as diatoms ${ }^{5,6}$, which eventually contribute to secondary export of organic matter out of the photic zone. Yet, the direct gravitational settling of diazotrophs themselves to the deep ocean has rarely been assessed.

Diazotrophs may associate with sinking particles and contribute to direct export by different mechanisms. The most direct ones include gravitational settling of individual cells/filaments or aggregates. According to Stokes' Law, particle sinking velocity scales with the square of particle size. Therefore, large particles should sink faster and are more likely to reach the deep ocean before being remineralized by bacteria ${ }^{7}$. Aggregation is thus a crucial step for the transport of small phytoplankton species which could export particulate organic carbon (POC) and N (PON) in similar proportion to their production in surface waters ${ }^{8}$. Diazotrophs have diverse morphologies and their size spans several orders of magnitude. Some types such as the free-living unicellular diazotrophic cyanobacteria (UCYN from groups $B$ and $C)$ are small $(2-8 \mu \mathrm{m}$ in diameter), while others such as Trichodesmium sp. are filamentous and can form large-sized colonies $(>100-1000 \mu \mathrm{m})$. In addition, some diazotrophs live in symbiosis with calcified (UCYN-A, $\sim 1 \mu \mathrm{m}$ ) or silicified eukaryotes (Richelia sp., Calothrix sp., $>20 \mu \mathrm{m}$, forming Diatom-Diazotrophic Associations or DDAs). These dense biominerals may provide ballast enhancing the downward export of these symbioses into the deep ocean. Therefore, the presence of different diazotrophs in surface waters may result in drastically different POC and PON export fluxes via the biological pump. Yet, no field observations have related individual diazotroph groups to the magnitude of downward particles fluxes to date.

Thanks to their inherently ballasted character, DDAs are well known to contribute to particulate matter export ${ }^{9,10}$, and are involved in seasonal peaks of POC export to the deep sea $(4000$ $\mathrm{m}$ ) in the North Pacific subtropical gyre ${ }^{11}$. Trichodesmium is one of the major contributors to global $\mathrm{N}_{2}$ fixation $^{12}$. However, Trichodesmium are thought to have a limited export capacity and to be preferentially remineralized in the surface layers due to the presence of gas vesicles providing them buoyancy, 13,14 . Yet, some studies have reported the presence of Trichodesmium in sediment traps material in the Kuroshio Current ${ }^{15}$, the tropical North Atlantic ${ }^{16}$, North ${ }^{17}$ and Pacific Oceans ${ }^{18}$. Intact filaments and colonies of Trichodesmium sp. have also been reported as deep as 3000-4000 $\mathrm{m}$ in the 
tropical Atlantic, Pacific and Indian Oceans ${ }^{16,19}$, but their contribution to organic matter export has yet to be quantified.

Theoretically, UCYN may not contribute importantly to POC export fluxes either due to their small size. Yet, Berthelot et al. ${ }^{20}$ reported in experimental mesocosms that primary production supported by UCYN was twice as more efficient in promoting POC export than production supported by DDA. During the same study, Bonnet et al..$^{21}$ showed that the sinking of UCYN-B and $\mathrm{C}$ was driven by the aggregation of small individual cells $(5-6 \mu \mathrm{m})$ into larger aggregates $(100$ to $>500 \mu \mathrm{m})$ that were eventually exported and accounted for up to $\sim 20 \%$ of the POC flux. Recently, Caffin et al. ${ }^{18}$ confirmed the presence of UCYN-B in sinking particles collected with sediment traps $(330 \mathrm{~m})$ throughout the western tropical South Pacific Ocean (WTSP) $\left(10^{3}\right.$ to $10^{7}$ nifH gene copies $\mathrm{L}^{-1}$ of trap material). Finally, Farnelid et al. ${ }^{22}$ observed nifH gene sequences in exported material $(150 \mathrm{~m})$ in the North Pacific subtropical gyre and found that all the diazotroph groups above as well as non-cyanobacterial diazotrophs were present in the samples.

Taken together, these studies suggest that all diazotroph groups, small or large, free-living or symbiotic, ballasted or not, have been detected below the photic layer. However, a detailed examination relating types of diazotrophs to the magnitude of downward particles fluxes and their contribution is needed to refine our understanding of their role in the magnitude and mechanisms controlling the biological carbon pump. This is even more timely as climate models predict an expansion of the oligotrophic gyres ${ }^{23}$, ${ }^{24}$, where diazotrophs represent a major component of the plankton biomass and sustain most new primary production ${ }^{25}$.

Here, we examine the species-specific fate of diazotrophs in the mesopelagic ocean. We used an innovative approach consisting of the combined deployment of surface-tethered drifting sediment traps, Marine Snow Catcher (MSC), and Bottle-net, in which we performed nifH sequencing and quantitative PCR on major diazotroph groups across the WTSP in parallel with biogenic element export fluxes quantification (Fig. 1a). This study builds up on prior investigations that have characterized this region as a hotspot for marine $\mathrm{N}_{2}$ fixation ${ }^{26}$. We show that all globally-significant $\mathrm{N}_{2}$ fixing cyanobacteria and non-cyanobacterial diazotrophs are systematically present in sinking particles down to $1000 \mathrm{~m}$, where they account for a large fraction of exported PON (52-100\%). Small size UCYN $(1-8 \mu \mathrm{m})$ are exported more efficiently than large filamentous diazotrophs under the form of large $(>50 \mu \mathrm{m})$ aggregates linked by an extracellular matrix. Globally, our analysis of the Tara Oceans metagenomes confirms that diazotrophs are always detected in mesopelagic waters when present in surface waters, revealing that the gravitational settling of diazotrophs is an important pathway for diazotroph-derived export production, influencing the ability of our ocean to sequester carbon.

\section{Results and discussion}

\section{Surface conditions}

The study region was characterized by typical oligotrophic waters (chlorophyll concentrations $<0.15 \mu \mathrm{g}$ $\mathrm{L}^{-1}$, DCM 100-180 m) east and west of Tonga, corresponding to the first group of stations S01, S02, S07 and S08 (Fig. 1a). The second group of stations (S03, S04, S05, S10, S11) was located in mesotrophic waters (chlorophyll $>0.15 \mathrm{\mu g} \mathrm{L}^{-1}$, DCM 70-90 m) in the vicinity of the Tonga volcanic arc (Fig. 1a). Surface $(0-50 \mathrm{~m})$ nitrate concentrations were consistently close or below the detection limit $\left(0.05 \mu \mathrm{mol} \mathrm{L} \mathrm{L}^{-1}\right)$ throughout the transect, while phosphate concentrations were typically $0.1 \mu \mathrm{mol} \mathrm{L}^{-1}$ at oligotrophic stations and depleted down to detection limit $\left(0.05 \mu \mathrm{mol} \mathrm{L}^{-1}\right)$ at mesotrophic stations, likely due to consumption by higher plankton stocks (Fig. S1). Seawater temperature ranged from 23.1 to $27.3^{\circ} \mathrm{C}$ in the mixed layer $(0-15 \mathrm{~m}$ to $0-60 \mathrm{~m})$ determined according to de Boyer Montégut et al. $(2004)^{27}$ (Fig. S1).

The abundances of key diazotroph groups indicated that UCYN-A1 were present at high abundances throughout the photic layer $(0-130 \mathrm{~m})$ of the transect (average $3.2 \times 10^{8}$ nifH gene copies $\mathrm{L}^{-1}$ ) (Fig. $1 \mathrm{~b}$ ), peaking at oligotrophic stations (average $1.1 \times 10^{9}$ nifH gene copies $\mathrm{L}^{-1}$ ). Trichodesmium was the second most abundant group, particularly in the vicinity of Tonga (average $1.3 \times 10^{7}$ nifH gene copies $\left.L^{-1}\right)$, followed by UCYN-B $\left(5.7 \times 10^{5}\right.$ nifH gene copies $\left.L^{-1}\right)$. UCYN-C and Gamma-A (a noncyanobacterial diazotroph) were also detected throughout the transect albeit at lower abundances $\left(10^{2}\right.$ to $10^{4}$ nifH gene copies $\mathrm{L}^{-1}$ ).

\section{How efficient are different diazotrophs groups to export?}

We first examined the nifH gene community composition of particles collected in drifting sediment traps located at $170 \mathrm{~m}, 270 \mathrm{~m}$ and $1000 \mathrm{~m}$ at stations S05M and S10M (Fig. 1a). On average, 32\% of the retrieved Amplicon Sequence Variants (ASV) corresponded to cyanobacteria genera over both stations (Fig. 2). The most abundant genus was Trichodesmium sp., but ASVs related to 
119 Crocosphaera watsonii (UCYN-B), Candidatus Atelocyanobacterium thalassa (UCYN-A) and contributed little to the percentage reads. Besides autotrophic diazotrophs, $68 \%$ of ASVs were affiliated to non-cyanobacterial diazotrophs including Alpha-, Beta-, and Gammaproteobacteria at both stations.

Amplicon sequencing provides relative abundances, which are not necessarily indicative of the abundance of the target microorganism in the natural environment ${ }^{28,29}$. Hence, to assess the export capacity of individual diazotroph groups, we quantified the abundance of five groups spanning different forms, sizes, lifestyle (symbiotic or not), using qPCR assays (UCYN-A1 symbiosis, UCYN-B, UCYN-C, Trichodesmium and Gamma-A; see Methods). DDAs were not quantified as they were almost not detected on microscopy inspections, pointing to their rarity in those waters at the time of the cruise. All five groups were detected at abundances ranging from $10^{3}$ to $10^{8}$ nifH gene copies $\mathrm{L}^{-1}$ of traps material, the highest being reported for UCYN-A1 and the lowest for UCYN-C (Fig. 3a,b). The diazotrophs assemblage exported to sediment traps generally reflected that of the photic layer, although some diazotrophs seemed to sink more efficiently than others: the highest diazotroph export fluxes were measured for UCYN-A1 at both sites and all depths of traps deployment $\left(5.0 \pm 1.1 \times 10^{8}\right.$ to $8.5 \pm 2.0 \times 10^{9}$ nifH gene copies $\left.\mathrm{m}^{-2} \mathrm{~d}^{-1}\right)$, followed either by UCYN-B $\left(2.2 \pm 0.9 \times 10^{7}\right.$ to $7.5 \pm 1.4 \times$ $10^{7}$ nifH gene copies $\left.\mathrm{m}^{-2} \mathrm{~d}^{-1}\right)$ or Trichodesmium $\left(2.5 \pm 1.9 \times 10^{6}\right.$ to $1.2 \pm 0.3 \times 10^{8}$ nifH gene copies $\mathrm{m}$ $\left.{ }^{2}\right)$ depending on station and depth (Fig. 3a,b). Gamma-A and UCYN-C were also exported, albeit at lower rates $\left(\sim 10^{5}\right.$ and $\sim 10^{6}$ nifH gene copies $\mathrm{m}^{-2} \mathrm{~d}^{-1}$, respectively).

Specific export turnover rates provide information on the rate at which diazotrophs are "lost" from the photic layer due to export (Turnover rate $\left(d^{-1}\right)=$ export flux/abundance in the photic layer). The range of calculated rates $\left(0.7 \pm 1.2 \times 10^{-5}\right.$ to $\left.11.2 \pm 1.9 \times 10^{-3} \mathrm{~d}^{-1}\right)$ spans through two orders of magnitude and varied depending on the diazotroph group, depth and station considered. On average (over all stations and depths), the export turnover rate of UCYN $\left(5.5 \pm 3.1 \times 10^{-3} \mathrm{~d}^{-1}\right.$ ) was ca. four times higher than that of Trichodesmium $\left(1.3 \pm 2.2 \times 10^{-3} \mathrm{~d}^{-1}\right)$ (Fig. 3c), pointing to preferential export of UCYN groups relative to the filamentous Trichodesmium. Among UCYN groups, the highest export turnover rate was measured for UCYN-B, followed by UCYN-C and UCYN-A1, although differences were not significant between groups (Mann-Whitney test, $\mathrm{p}<0.05$ ). The export turnover rate of Gamma-A (average $1.8 \pm 1.5 \times 10^{-3} \mathrm{~d}^{-1}$ ) was intermediate between that of Trichodesmium and UCYN groups.

Epifluorescence microscopy confirmed the presence of phycoerythrin-containing UCYN-B and UCYN-C-like cells in sediment trap samples (Fig. 4a-f). Scanning electron microscopy revealed that they were recurrently found embedded in large organic aggregates, or organized into clusters of tens to hundreds of cells linked by an extracellular matrix (Fig. $4 \mathrm{~g}-\mathrm{I}$ ), which was further confirmed by Alcian blue straining (Fig. S2). Trichodesmium was also observed in all samples, mostly as free filaments, but intact colonies were observed in sediment trap samples especially at $1000 \mathrm{~m}$ at both stations. Gamma-A and UCYN-A1 cannot be visualized by these techniques and are thus assessed solely on the basis of qPCR counts (above).

Pigment concentrations measured in sediment trap samples at both stations indicate that total pigment concentrations and diversity decreased with depth. Apart from the degradation pigments phaeophorbide and phaeophytin, zeaxanthin, a biomarker of cyanobacteria predominated at all depths (Fig. S3). The Chlorophyll a : phaeopigments ratios were elevated (average 1.8, range 0.8-3.), indicative of fresh organic matter in sediment trap samples.

\section{Contribution of diazotrophs to PON export fluxes}

Sediment trap-based PON export fluxes at $170 \mathrm{~m}, 270 \mathrm{~m}$ and $1000 \mathrm{~m}$ ranged between $1.6 \pm 0.2$ and $6.1 \pm 1.2 \mathrm{mg} \mathrm{N} \mathrm{m}^{-2} \mathrm{~d}^{-1}$ at S05M and $5.2 \pm 0.1$ and $13.4 \pm 1.3 \mathrm{mg} \mathrm{N} \mathrm{m}^{-2} \mathrm{~d}^{-1}$ at S10M (Table 1). Fluxes attenuated with depth, with transfer efficiencies of 0.02 and 0.03 between $170 \mathrm{~m}$ and $1000 \mathrm{~m}$ at both stations. The $\mathrm{N}$ export efficiency (Ne-ratio, the amount of PON export at the base of the euphotic zone over the integrated $\mathrm{N}_{2}$ fixation rate) was $18 \%$ and $53 \%$ at stations $\mathrm{S} 05 \mathrm{M}$ and S10M. The C:N ratios in exported material was lower (5.2) than that of the surface (7.5, integrated value over the photic layer) at station S10M, pointing to a preferential export of PON relative to POC.

The proportion of PON attributed to diazotrophs and collected by sediment traps was evaluated based on qPCR results and estimated PON content per diazotroph (see Methods). The PON flux attributed to diazotrophs ranged from $0.9-2.3 \mathrm{mg} \mathrm{N} \mathrm{m}^{-2} \mathrm{~d}^{-1}$ at S05M and from 1.2-2.7 $\mathrm{mg} \mathrm{N}$ $\mathrm{m}^{-2} \mathrm{~d}^{-1}$ at S10M, accounting for $18 \%(170 \mathrm{~m})$ to $100 \%(1000 \mathrm{~m})$ and $9 \%(170 \mathrm{~m})$ to $52 \%(1000 \mathrm{~m})$ of the total PON export flux at stations S05M and S10M, respectively (Table 1). Trichodesmium was the major contributor of the PON attributed to diazotrophs at $1000 \mathrm{~m}$ at both stations, whereas UCYN dominated at shallower depths (Table S1). Despite non-cyanobacterial diazotrophs were present in 
exported material (68\% of sequences), their $\mathrm{C}$ and $\mathrm{N}$ composition remains unknown due to the poor availability of cultured representatives. Thus, quantifying their contribution to export fluxes is not possible at this stage. In addition, sequencing data also revealed the presence of Katagnymene spp., which are large $(>100-1000 \mu \mathrm{m})$ and likely have high $C$ and $N$ content. Hence the contribution of diazotrophs to exported PON reported here likely represent a lower-end estimate.

\section{The fate of diazotrophs in the mesopelagic ocean}

We further assessed the fate of the exported diazotroph community by collecting fresh particles in mesopelagic waters using the Marine Snow Catcher (MSC, see Methods). In essence, the MSC allows separating non-sinking particles from slow sinking and fast sinking particles ${ }^{30}$ (see Methods). These different fractions can hence be studied individually. MSC samples were collected at the same depths as those of sediment traps $(170,270,1000 \mathrm{~m})$ at stations S05M and S10M and in addition at seven other stations (Fig. 1a).

The diazotroph community composition (based on nifH amplicon sequencing) in the various fractions generally mirrored that of traps at stations S05M and S10M with $32-54 \%$ of sequences affiliated with cyanobacteria and a prevalence of Trichodesmium (Fig. 5). This was also the case at stations S03, S04, S07 and S11, but not at stations S01, S02 and S08, where sequences assigned to Candidatus Atelocyanobacterium thalassa and Crocosphaera watsonii were generally more abundant than Trichodesmium sequences. As in sediment traps, a large number of nifH sequences (46-58\%) were affiliated to non-cyanobacterial diazotrophs, whose composition was overall consistent with that of the traps, although some classes not detected in sediment traps (Epsilonproteobacteria and Clostridia) were present in all MSC fractions. In general, the total number of nifH gene reads was consistently $10-25 \%$ higher in the slow and fast sinking fractions compared to the suspended fraction at all stations. This trend was mainly driven by non-cyanobacterial sequences that are suspected to be attached to particles ${ }^{31}$, and to a lesser extent by sequences affiliated with cyanobacteria.

As in sediment traps, five diazotroph groups were quantified in the suspended, slow and fast sinking fractions to more finely assess their sinking dynamics over short time scales (h). Overall, UCYN-A1 and Trichodesmium were the most abundant groups in the mesopelagic MSC samples (170 $\mathrm{m}$ to $1000 \mathrm{~m}$ ), and their numbers varied in parallel with the abundance of their population in the photic layer (Fig. 6). UCYN-A1 were the most abundant at oligotrophic stations (S01, S02, S07, S08, chlorophyll $<0.15 \mu \mathrm{g} \mathrm{L}^{-1}$ ), while Trichodesmium peaked at mesotrophic stations (Chlorophyll a $>0.15$ $\mu \mathrm{g} \mathrm{L}^{-1}$, Fig. 1). Conversely, the abundance of UCYN-B, UCYN-C and Gamma-A in mesopelagic waters was poorly correlated with their photic layer abundance.

The MSC suspended fraction accounted for the most abundant pool of diazotrophs at all stations, followed by either the slow or the fast sinking pools, depending on groups (Fig. 6a-e). At the mooring stations S05M and $\mathrm{S} 10 \mathrm{M}$, the total concentration of diazotrophs and the diazotroph community composition remained generally constant at the three sampled depths $(170 \mathrm{~m}, 270 \mathrm{~m}$ and $1000 \mathrm{~m}$ ), consistent with the results observed in sediment traps. To evaluate the export potential of each individual diazotroph group, we calculated the ratio of sinking versus non-sinking cells (the sum of the slow and fast sinking fractions over the total). The proportion of sinking cells varied widely across the transect, but was the highest for UCYN-A1 (32 $\pm 33 \%)$, UCYN-C (31 $\pm 38 \%)$, Gamma-A $(29 \pm 19 \%)$ and UCYN-B (27 $\pm 11 \%)$, and the lowest for Trichodesmium (18 $\pm 20 \%)$ (Fig. 6f). Among the sinking fractions, UCYN-B and Gamma-A were generally equally distributed among the slow and fast sinking fractions, whereas the majority of $\mathrm{nifH}$ gene copies were found in the fast sinking fraction for UCYN-A1 (59\%), UCYN-C (62\%) and Trichodesmium (67\%). Taken together, these results indicate that over short time scales ( $2 \mathrm{~h}$, the conventional settling of particles following MSC deployment ${ }^{30}$ ): i) small UCYN (few $\mu \mathrm{m}$ ) generally sink more efficiently than large Trichodesmium $(>100 \mu \mathrm{m})$, ii) when sinking, Trichodesmium sinks fast, iii) UCYN-A1 and UCYN-C sink faster than UCYN-B and Gamma-A. A detailed imaging study performed on $170 \mathrm{~m}$ MSC samples at the mooring stations S05M and S10M indicates that the $50-80 \%$ of phycoerythrin-containing UCYN in the fast sinking fraction were organized into aggregates of tens to $>250$ cells measuring 30 to $>100 \mu \mathrm{m}$, while the majority (60-95\%) of UCYN were free living in the suspended fraction (Figure S4). This indicates that under minimum turbulent agitation, UCYN quickly (within $2 \mathrm{~h}$ ) form aggregates large/dense enough to sink.

Concentrations of PON averaged across all stations $1.85 \pm 0.49 \mu \mathrm{g} \mathrm{L}^{-1}, 0.25 \pm 0.13 \mu \mathrm{g} \mathrm{L}^{-1}$ and $0.26 \pm 0.08 \mathrm{\mu g} \mathrm{L}^{-1}$ within the suspended, slow sinking and fast sinking fractions (Fig. S5a). PON in the fast sinking fraction contributed $11 \pm 2 \%$, while the slow sinking and suspended fractions contributed $11 \pm 4 \%$ and $79 \pm 5 \%$ in terms of total PON. Thus, 22\% of the PON was sinking out of the upper part of the MSC within $2 \mathrm{~h}$ during our study. We converted transparent expolymeric particles into $\mathrm{C}$ (TEP-C), that revealed higher concentrations in the suspended fraction compared to the fast sinking 
fraction at all stations (TEP-C concentrations were null in the SS fraction) (Fig. S5b). The TEP-C:POC ratio was generally higher in the suspended fraction compared to the fast sinking. This indicates that, despite UCYN were embedded in TEPs in FS samples, cells rather than TEPs were the major contributor of the POC pool in the FS fraction.

Finally, we quantified diazotrophs on vertical profiles spanning the water column between 200 $\mathrm{m}$ and $2000 \mathrm{~m}$ by using a Bottle-net mounted on the CTD rosette frame at six stations across the transect (Fig. 1a). The bottle-net consists of a $20-\mu \mathrm{m}$ conical plankton net housed in a cylindrical PVC pipe ${ }^{19}$. The top cover is opened at the desired bottom depth $(2000 \mathrm{~m})$ of the tow, remains opened during the ascent of the rosette, and closed again at the upper depth $(200 \mathrm{~m})$ of the water column to be sampled. This results in one integrated sample of $200 \mathrm{~m}$ to $2000 \mathrm{~m}$ per deployment. Overall, bottlenet tows confirm that diazotrophs are consistently present in this deep ocean layer, with concentrations averaging $1.4 \times 10^{7} \mathrm{nifH}$ gene copies $\mathrm{m}^{-2}$. Among the groups targeted by qPCR, the community was primarily dominated by UCYN-A1 $(63 \%$ on average over all sampled stations) and Trichodesmium (27\%), and secondarily by UCYN-B (9\%) (Fig. 7), generally mirroring the diazotroph community in surface water (these numbers are conservative and may be underestimated as some individual UCYN pass through the $20 \mu \mathrm{m}$ mesh net of the bottle-net). The $2000-200 \mathrm{~m}$ stock was relatively constant among stations, except at the most oligotrophic station S08, where it was lower by two orders of magnitude than that of other stations.

\section{Beyond subtropical south Pacific waters}

To assess whether the sinking of globally-distributed diazotrophs down to mesopelagic waters is a widespread feature, we explored the presence of diazotrophic cyanobacterial genomes using Tara Oceans metagenomes collected from other ocean basins ${ }^{32}$, 33 . Among all the stations for which metagenomic samples from both surface and mesopelagic were available, we selected those ones showing significant abundances of nifH metagenomic reads in surface waters $(5 \mathrm{~m})^{32}$. This led to a total of five stations located in the South Atlantic and North and South Pacific oceans where we also explored the presence of diazotrophs, at the genome level, in the mesopelagic (300 to $800 \mathrm{~m}$ ) (Fig. 8). Recruitment of metagenomic reads against representative genomes of the diazotrophic community (Trichodesmium, Richelia, UCYN-B and UCYN-A1 and UCYN-A2; Table S2) across different sizefractions in surface and mesopelagic waters show that diazotrophs in general were systematically detected in mesopelagic waters at all five stations (Fig. 8; Table S3 ; see Methods). As in the WTSP, every specific group was detected at depth when present in surface, except when abundances in surface were very low ( $<6.7$ reads/total 100,000 reads). Accordingly with their cell size, Trichodesmium, Richelia, UCYN-B and UCYN-A2 reads were recovered in the size fraction $>3 \mu \mathrm{m}$ at mesopelagic depths, whereas the UCYN-A1 symbiosis was recovered in the $0.2-3 \mu \mathrm{m}$ and $0.8-3 \mu \mathrm{m}$ size fractions. Overall, this metagenomic analysis shows that the export of diazotrophs through gravitational settling is not restricted to the WTSP and is a widespread phenomenon in the tropical ocean.

\section{Biogeochemical implications}

Excluding silicified DDAs ${ }^{11}$, diazotrophs have seldom been regarded as important contributors to organic matter export. Yet, our results provide clear evidence that they are present and ubiquitous in the mesopelagic ocean and they contribute significantly to the PON export fluxes in the WTSP. They present, however different behaviors.

We showed that diazotroph cell sizes is not necessarily a key variable controlling the diazotrophs' ability to sink out the euphotic zone. Small UCYN (1-8 $\mu \mathrm{m})$ displayed the highest export turn-over rates $\sim 10^{-3} \mathrm{~d}^{-1}$, in the range or higher than those reported for ballasted phytoplankton groups such as diatoms and coccolithophores ${ }^{34}$. Within UCYN, UCYN-A1 clearly dominated the diazotroph community targeted by qPCR in mesopelagic waters of the WTSP. Although the UCYN-A1 symbiosis has been detected once in mesopelagic waters of the South Atlantic Ocean ${ }^{32}, 35$, their capacity to leave the photic layer and sink throughout the mesopelagic zone down to $1000 \mathrm{~m}$ (Fig. 3, 8) has not been thoroughly explored before. As UCYN-A rank among the most abundant diazotrophs in the global ocean ${ }^{12}$ and span from tropical to polar waters ${ }^{36,37}$, we suggest that they potentially play a significant contribution to ocean organic matter sequestration. Some UCYN-A ecotypes (e.g. UCYNA2) live in obligate symbiosis with a calcified coccolithophore ${ }^{38}$, hence their export is likely enhanced by this ballast mineral increasing the density of sinking particles to which they are associated. In future studies, better constrains on UCYN-A sedimentation rates and aggregation processes would be of primary importance to assess their role in particle fluxes and cycling.

UCYN-B and $-C$ are free-living unicellular cyanobacteria and their export pathway therefore does not rely on mineral ballasted hosts. Our results indicate that the sinking of such small cells is 
made possible through the aggregation of UCYN into large-sized aggregates $(30->100 \mu \mathrm{m})$ of tens to hundreds of cells, large/dense enough to sink, in accordance with a previous mesocosm study ${ }^{21}$. The presence of UCYN-B in sediment traps is also in accordance with previous reports of Crocospheara watsonii sequences at station ALOHA either just below the euphotic zone ${ }^{22}$, or as deep as $4000 \mathrm{~m}^{39}$. The visualization of our sediment trap samples shows that they can be subsequently embedded in mixed aggregates with other cells and debris (Fig. 4, S2). The UCYN-B large $(>4 \mu \mathrm{m})$ ecotype, which was dominating in this study (data not shown), produces large amounts of C-rich transparent exopolymeric particles (TEP) at rates one to two order of magnitude higher than that of diatoms and coccolithophorids ${ }^{40}$, probably in response to nutrient limitation and excess light ${ }^{41}$. In cultures of Crocosphaera watsonii, TEP account for $\sim 22 \%$ of the particulate $\mathrm{C}$ pool ${ }^{40}$. Hence, TEP produced by UCYN-B do not only provide a matrix for the formation of large aggregates, but may also account for a significant fraction of $C$ export. TEP are indeed greatly enriched in $C$ relative to $N\left(C: N \sim 25^{40}\right)$.

Trichodesmium was generally the second contributor to the diazotroph community targeted by qPCR in mesopelagic waters after UCYN-A1, which contradicts the common assertion that they are entirely remineralized in the euphotic layer, ${ }^{4}$. Several potential mechanisms could explain the presence of Trichodesmium in mesopelagic waters. Trichodesmium colonies can migrate vertically to exploit the deep phosphate stock (Villareal and Carpenter 2003) (the phosphacline was around $200 \mathrm{~m}$ in our study region at the time of the cruise). According to this theory, they overcome their positive buoyancy by fixing $C$ that result in carbohydrate ballasting. However, Walsby $(1978)^{42}$ observed that $100 \%$ of the gas vacuoles of Trichodesmium erythraeum (the most abundant species in this study) collapse at depths between $105 \mathrm{~m}$ and $120 \mathrm{~m}$, resulting in a loss of their buoyancy. Hence, Trichodesmium could be locked in a persistent and irreversible downward trajectory. Alternatively, Berman-Frank et al. ${ }^{43,44}$ have shown that programmed cell death induces internal cellular degradation, gas-vacuole loss and increased production of TEP, resulting in an increase in the vertical flux of Trichodesmium ${ }^{45}$. Whatever the mechanism behind the vertical flux of Trichodesmium, we report here higher abundances at $1000 \mathrm{~m}$ compared to those at shallower depths at both stations, consistent with microscopic observations showing intact colonies at $1000 \mathrm{~m}$. This likely results from a spatio-temporal decoupling between production and export ${ }^{46}$. Despite sinking less efficiently than UCYN in the aggregates, they are much larger and contain more $\mathrm{C}$ and $\mathrm{N}$ per filament than UCYN ${ }^{12}$, and accounted for a significant fraction of the diazotroph-attributed PON export in this study, especially at $1000 \mathrm{~m}$ (Table S1), which is in accordance with previous studies reporting intact Trichodesmium colonies down to $3000-4000 \mathrm{~m}^{16,19}$.

More than $90 \%$ of the organic matter sinking below the euphotic zone is respired before it reaches a depth of $1000 \mathrm{~m}^{7}$. Fast sinking particles will therefore theoretically make a greater contribution to the deep ocean flux than slow sinking particles, since the latter will be rapidly recycled at shallow depths. The relative similarity of the taxonomic diazotroph community composition in mesopelagic waters sampled by three independent sampling approaches (traps, bottle-net, and MSC) compared to the diazotrophic composition of the euphotic layer suggests a rapid export mode of diazotrophs. This is further confirmed by i) the high proportion of diazotroph groups quantified in the MSC fast sinking fraction, ii) the whole cells and colonies and high Chlorophyll $a$ : pheopigments ratios in sediment traps, indicative of healthy phytoplankton (Fig. 4; S2). Finally, iii) while PON export fluxes were attenuated with depth in our study, which is a classical feature in the oligotrophic ocean ${ }^{47}$, the diazotroph export fluxes were not, suggesting a high transfer efficiency to the deep ocean, and thus sinking velocities high enough to escape short-term remineralization. Indeed, a parallel study performed during the same cruise ${ }^{48}$ reveals significant $\mathrm{N}_{2}$ fixation rates in sediment traps and MSC samples, suggesting that part of the diazotroph community in mesopelagic waters sunk fast enough to remain alive at mesopelagic depths. Bar-Zeev et al. ${ }^{45}$ reported sinking velocities of Trichodesmium erythraeum of $\sim 200 \mathrm{~m} \mathrm{~d}^{-1}$. More recently, Ababou et al. ${ }^{49}$ reported sinking velocities of Trichodesmium erythraeum and UCYN aggregates formed in roller tanks of $92 \pm 37 \mathrm{~m} \mathrm{~d}^{-1}$ and $333 \pm 176 \mathrm{~m} \mathrm{~d}^{-1}$, respectively. We calculated that Trichodesmium sinking at those rates $\left(92-200 \mathrm{~m} \mathrm{~d}^{-1}\right)$ would take 5 to 10 days to reach $1000 \mathrm{~m}$, whereas UCYN would take 3 days, which would be compatible with finding active cells observed at those depths ${ }^{48}$.

\section{Conclusion}

Our findings challenge the common assumption that the fate of diazotroph-derived production is constrained to the surface layer. They provide a significant advance in defining the role of diazotrophs on an important planetary carbon flux, the biological carbon pump, and bring new insights into the species-specific export of diazotrophs in the ocean, revealing the previously-unseen role of UCYN and Trichodesmium into the overall export fluxes. Diazotrophs being not restricted to the tropical ocean, it 
416

417

would be interesting in future studies to explore the direct gravitational export of diazotrophs in temperate and polar waters.

Direct export through gravitational settling of diazotrophs is most likely only the tip of the iceberg and diazotrophs can potentially be exported through secondary pathways: diazotrophs release in seawater $10-50 \%$ of recently fixed $\mathrm{N}_{2}$ (referred to as Diazotroph Derived, DDN) as $\mathrm{NH}_{4}{ }^{+}$and dissolved organic $\mathrm{N}(\mathrm{DON})^{50,51,52}$. This $\mathrm{DDN}$ is potentially available for assimilation by the surrounding phytoplanktonic communities, supporting their growth and leading a potential secondary (indirect) export pathway of diazotroph-derived $\mathrm{OC}^{6,21,53}$. Moreover, DDN is also transferred to zooplankton, which produces dejections termed fecal pellets, that sink fast and play a major role in OC export to the deep ocean ${ }^{54}$. In future studies, there is an urgent need to develop appropriate approaches to decipher diazotroph export pathways (direct $v s$ indirect) if we are to understand the role of $\mathrm{N}_{2}$ fixation in the biological carbon pump. This is an especially pressing question given that current climate models predict an expansion of the oligotrophic gyres $\left(60 \%\right.$ of our oceans) ${ }^{23,24}$, where diazotrophs thrive. $\mathrm{N}_{2}$ fixation will thus likely be crucial to supporting primary productivity and export in the future ocean.

\section{Methods}

Samples were collected during the TONGA cruise (Fig. 1, DOI: 10.17600/18000884) in the tropical South Pacific Ocean onboard the R/V L'Atalante from November 1 to December 5 2019. We collected suspended and sinking particles in the mesopelagic zone using three complementary devices: surface-tethered drifting sediment traps ${ }^{55}$, MSC and Bottle-net. Additionally, water column samples were collected from the euphotic layer using Go-Flo bottles mounted on a trace metal clean rosette to quantify the stocks of the major groups of diazotrophs in the photic layer.

Satellite products and photic layer sampling. Satellite-derived surface chlorophyll a concentration during the TONGA cruise (November 2019) was accessed at http://oceancolor.gsfc.nasa.gov (MODIS Aqua, $4 \mathrm{~km}$, 8-days composite, level 3 product). Vertical $0-150 \mathrm{~m}$ depth profiles were performed at each station using a trace metal clean titanium rosette of Go-Flo bottles equipped with a fluorometer and temperature, conductivity and oxygen sensors. Seawater samples were collected from 5 depths $(75,50,20,10,1 \%$ surface irradiance levels) to quantify the stock of major groups of diazotrophs in the photic layer by quantitative PCR (qPCR) as described below. Additionally, primary production and $\mathrm{N}_{2}$ fixation rates were measured in triplicates at the same six depths at the locations of the traps deployments (S05M and S10M), as described in ${ }^{56,57} . \mathrm{N}_{2}$ fixation rates were measured at two occasions (on day 1 and day 3 of the traps deployment). The average value between both profiles was used to calculate the e-ratios (POC export:primary production) and the contribution of $\mathrm{N}_{2}$ fixation to primary production rates.

Sediment trap deployment and sample analyses. A surface tethered mooring line ( 1000 m long) was deployed at stations S05M $\left(21.157^{\circ} \mathrm{S} ; 175.153^{\circ} \mathrm{W}, 5\right.$ days $)$ and S10M $\left(19.423^{\circ} \mathrm{S} ; 175.133^{\circ} \mathrm{W}, 4\right.$ days). The line was equipped with sediment traps (KC Denmark $\left.{ }^{\circledR}\right)$ at 3 depths: $170 \mathrm{~m}$ (corresponding to the base of the photic layer), $270 \mathrm{~m}$ and $1000 \mathrm{~m}$. Each trap was composed of four particle interceptor tubes (PITs) mounted on a cross frame (collecting area of $0.0085 \mathrm{~m}^{2}$, aspect ratio of 6.7 ). Two of the tubes were used for this study: one tube was used for biogeochemical analyses (hereafter referred to as 'Biogeo' tube), and one for microbiological analyses ('Microbio' tube). Prior to deployment, the tubes were filled with $0.2 \mu \mathrm{m}$ filtered seawater with added saline brine $\left(50 \mathrm{~g} \mathrm{~L}^{-1}\right)$. Borate-buffered formalin (5\%) was also added to the Biogeo tube to prevent in situ microbial decomposition ${ }^{55}$. After recovery, the density gradient was visually verified, and the PITs were allowed to settle for $2 \mathrm{~h}$ before the supernatant seawater was carefully removed with a peristaltic pump. The remaining water containing the sinking material was transferred to a chlorohydric acid-washed container, while being screened with a $500 \mu \mathrm{m}$ mesh to remove swimmers (zooplankton that actively entered the traps) ${ }^{58}$. Subsequently, samples were split into 12 aliquots. A triplicate set of aliquots were filtered onto 25-mm diameter Supor filters for nifH sequencing and nifH qPCR as described below. Another triplicate set of aliquots were filtered onto $25-\mathrm{mm}$ diameter combusted $\left(4 \mathrm{~h}, 450^{\circ} \mathrm{C}\right)$ glass microfiber filters (Whatman GF/F), which were subsequently dried for $24 \mathrm{~h}$ at $60^{\circ} \mathrm{C}$, pelleted and from which particulate $\mathrm{N}(\mathrm{PON})$ and $\mathrm{C}(\mathrm{POC})$ were analyzed by EA-IRMS (Elemental Analyzer-Isotope Ratio Mass Spectrometry) using an Integra 2 (Sercon) mass spectrometer. Lastly, a triplicate set of aliquots was filtered on GF/F filters for further pigment analyse ${ }^{59}$, and another triplicate filtered on 1 $\mu \mathrm{m}$ polycarbonate filters for microscopic analyses (see below for methods).

\section{MSC deployment}


418

419

420

421

422

423

424

425

426

427

428

429

430

431

432

433

434

435

436

437

438

439

440

441

442

443

444

445

446

447

448

449

450

451

452

453

454

455

456

457

458

459

460

461

462

463

464

465

466

467

468

469

470

471

472

473

474

475

476

477

Suspended and sinking particles were sampled using a MSC at 3 depths at the mooring stations S05M and S10M (170 m, $270 \mathrm{~m}$ and $1000 \mathrm{~m})$, and at $200 \mathrm{~m}, 400 \mathrm{~m}$ and $1000 \mathrm{~m}$ at S8. Additionally, the MSC was deployed at $200 \mathrm{~m}$ at S01, S02, S03, S04, S05V, S07, S10V and S11 (Fig. 1). The MSC is a large volume water sampler $(100 \mathrm{~L})$ that collects sinking particles with minimal turbulent agitation $^{60}$. Upon recovery, the MSC is placed on deck for $2 \mathrm{~h}$ while any particles present settle onto the base of the bottom $7 \mathrm{~L}$ chamber. After each recovery, the MSC is conventionally left on deck for 2 $\mathrm{h}$ allowing particles to settle $\mathrm{e}^{30}$. Fast sinking particles were thereby deposited collected in a dedicated plate at the bottom of the MSC, slow sinking particles were collected from the 7-litre compartment above the plate, and the non-sinking (or suspended) fraction was collected from the upper part of the $\mathrm{MSC}^{30}$. All three fractions were collected separately $(4 \mathrm{~L}$ for the suspended, $1.2 \mathrm{~L}$ for the slow sinking). For the fast sinking fraction, the entire volume of the plate was sampled (280 to $310 \mathrm{~mL}$ ). Subsamples from each fraction were filtered for PON and POC quantification, TEP quantification according to Passow and Alldredge (1995) ${ }^{61}$, microscopic observations, and nifH sequencing, nifH qPCR as described below. We used the formula described in Riley et al., $(2012)^{30}$ to obtain values associated with fast or slow sinking particles only, quantitatively removing the contribution of other fractions.

\section{Bottle-net deployment}

Vertical 2000-200 m profiles were done using a bottle-net mounted on the CTD rosette frame at stations S03, S04, S05M, S07, S08, S10M, S11 and S12. The bottle-Net consists of a 20- $\mu \mathrm{m}$ conical plankton net housed in a cylindrical PVC pipe ${ }^{19}$. It is lowered with the top cover closed, which is opened at the desired bottom depth (Db, $2000 \mathrm{~m}$ ) of the tow, remains opened during the ascension of the rosette, and closed again at the upper depth $(\mathrm{Du}, 200 \mathrm{~m})$ of the water column to be sampled. This results in one integrated sample of 2000 to $200 \mathrm{~m}$ per deployment. Once on deck, the bottle-nets were gently rinsed with filtered seawater before retrieving the sample from the collector. At each station, samples were split into aliquots that were processed for were analyzed for nifH qPCR. Sampled volume was estimated as the product between the cross-sectional area of the mouth of the bottle-Net $(7.5 \mathrm{~cm}$, aspect ratio of 4$)$ and the vertical distance covered by the device from the start of the ascension to the closure of the top cover $(1800 \mathrm{~m})$. Blank casts were performed with the bottle-net closed during the entire cast to assess for potential contaminations, and blanks were subtracted.

\section{nifH gene sequencing and bioinformatics}

The nifH gene was sequenced from a total of 71 samples: 18 samples collected from sediment traps deployed at $170 \mathrm{~m}, 270 \mathrm{~m}$ and $1000 \mathrm{~m}$ at S05M and S10M, and 53 samples collected from the suspended, slow sinking and fast sinking fractions of particles collected with the MSC. To that end, DNA was extracted using the DNeasy Plant Mini Kit (Qiagen, Courtaboeuf, France) with additional freeze-thaw bead beating and proteinase $K$ steps before the kit purification ${ }^{62}$. Triplicate nested PCR reactions were conducted using degenerate nifH primers ${ }^{63}$. The PCR mix was composed of $5 \mu \mathrm{L}$ of $5 \mathrm{X}$ MyTaq red PCR buffer (Bioline), $1.25 \mu \mathrm{L}$ of $25 \mathrm{mM} \mathrm{MgCl}_{2}, 0.5 \mu \mathrm{l}$ of $20 \mu \mathrm{M}$ forward and reverse primers, $0.25 \mu \mathrm{L}$ Platinum Taq and $5 \mu \mathrm{L}$ of DNA extract $(1 \mu \mathrm{L}$ on second round). The reaction volume was adjusted to $25 \mu \mathrm{L}$ with PCR grade water. Triplicate PCR products were pooled and purified using the Geneclean Turbo kit (MP Biomedicals). Partial adapters were added by ligation at the sequencing facility (Genewiz) and Ilumina MiSeq 2×300 paired end sequenced. Demultiplexed paired-end sequences were dereplicated, denoised, assembled and chimeras discarded using the DADA2 pipeline ${ }^{64}$. Fifty-thousand to 60,000 reads were obtained per sample. In total, $>2.9$ millions of high quality nifH sequences were obtained resulting in 14925 ASVs (submitted to NCBI with accession numbers SAMN19796776-SAMN19796835

). ASVs were annotated down to the genus level using a DADA2 formatted nifH gene database (https://github.com/moyn413/nifHdada2). Sequences were grouped into 17 genus according to the database, and sequences not identified to the genus level were grouped as "others". The nifH gene was successfully amplified from all samples.

\section{Abundance of diazotrophs et contribution to $\mathrm{N}$ export fluxes}

The abundance of diazotrophs was determined using TaqMan qPCR assays and previously published primer-probe sets for Trichodesmium, UCYN-A1, UCYN-B, UCYN-C and Y-24474A11 (the latter hereafter referred to as Gamma-A) targeting the nifH gene ${ }^{65,66,67}$. The qPCR was run in $25 \mu \mathrm{L}$ reactions consisting of $12.25 \mu \mathrm{L}$ TaqMan PCR Master Mix (Applied Biosystems, Villebon Sur Yvette, France), $1 \mu \mathrm{L}$ of the forward and reverse primers at $10 \mu \mathrm{M}$ (HPLC purified, Eurofins, Nantes, France), $0.25 \mu \mathrm{L}$ probe at $10 \mu \mathrm{M}, 8.25 \mu \mathrm{L}$ PCR grade water, $0.25 \mu \mathrm{L}$ bovine serum albumin at $10.08 \mu \mathrm{g} \mathrm{L}^{-1}$, and $2 \mu \mathrm{L}$ standard or template sample. The qPCR program was run on a CFX96 Real-Time System thermal cycler (BioRad, Marnes-la-Coquette, France) and consisted of 2 min at 50두, 10 min at $95^{\circ} \mathrm{C}$ 
continued by 45 cycles of $15 \mathrm{~s}$ at $95^{\circ} \mathrm{C}$ and $1 \mathrm{~min}$ at $64^{\circ} \mathrm{C}$. The annealing temperature was changed to $60^{\circ} \mathrm{C}$ for UCYN-A1 qPCR runs ${ }^{67}$. Standard dilutions $\left(10^{7}-10^{1}\right.$ gene copies) were run in duplicate, and samples and no-template controls (NTCs) in triplicate. NTCs did not show any amplification. The efficiency was $98-113 \%$. Inhibition tests were carried out on all samples and each primer-probe set by adding the $2 \mu \mathrm{L}$ of the $10^{5}$ copies standard to each sample. No inhibition was observed. The limit of detection and detected but not quantifiable limits were 1 and 8 gene copies per reaction, respectively.

The diazotroph turnover rate representing the fraction of surface diazotrophs exported out of the photic layer per day was calculated as follows: Turnover rate $\left(d^{-1}\right)=$ export flux/abundance in the photic layer. The proportion of PON collected by sediment traps attributed to diazotrophs was calculated based on estimated PON content per cell. For nanoplanktonic UCYN, cell dimensions were directly measured and their biovolume calculated ${ }^{68}$. The $C$ content per cell was estimated from the biovolume according to Verity et al. $(1992)^{69}$ and the $\mathrm{N}$ content calculated based on C:N ratios of 5 for UCYN-B ${ }^{70,71}$ and 8.5 for UCYN-C ${ }^{50}$. For the UCYN-A1-host symbiosis, we considered a size of $1 \mu \mathrm{m}$ for the UCYN-1 and $2 \mu \mathrm{m}$ for the host and a C:N ratio of $6.3^{72}$. For Trichodesmium, we considered the average value of $10 \mathrm{ng} \mathrm{N}$ per Trichodesmium filament from the same region ${ }^{73}$. To circumvent the polyploidy of Trichodesmium ${ }^{74}$, we divided the qPCR-based abundances by 12 . This ratio was determined for this study by dividing the qPCR-based abundances by the number of Trichodesmium filaments counted at S05M and S10M stations at 6 depths in the photic layer (we considered 100 cells per filament of Trichodesmium).

\section{Particle imaging}

Seawater samples from traps, MSC and bottle-nets were gently filtered on $0.2 \mu \mathrm{m}$ (for scanning electron microscopy, SEM) and $2 \mu \mathrm{m}$ polycarbonate filters (for epifluorescence microscopy) at very low pressure to preserve the particle structure. For epifluorescence microscopy, filters were fixed with paraformaldehyde (2\% prepared in filtered seawater) for 10 minutes at ambient temperature and stored at $-80^{\circ} \mathrm{C}$ until visualized using a Zeiss Axioplan (Zeiss, Jena, Germany) microscope fitted with a green $(510-560 \mathrm{~nm})$ excitation filter, which targeted the phycoerythrin-rich cells. For SEM, samples were fixed with $2.5 \%$ glutaraldehyde and $1.6 \%$ PFA for $1 \mathrm{~h}$ at room temperature. Subsequently, the filters were rinsed twice in $0.2 \mu \mathrm{m}$ filtered in seawater during $15 \mathrm{~min}$, rinsed in osmium during $30 \mathrm{~min}$, and rinsed thrice in filtered seawater to eliminate excess osmium. Next, the filters passed through a series of ethanol drying solutions (50,70, 95 and 100\%, 10 min each), and a series of HDMS solutions $(30,50,80$ and $100 \%, 10$ min each). Finally, the filters were air-dried and stored at room temperature until SEM analyses. The filters were visualized onshore using a Phenom-Pro benchtop scanning electron microscope at $10 \mathrm{kV}$.

\section{Tara Oceans sampling and reads recruitments in metagenomes}

23 metagenomes, collected from five stations along the Tara Oceans expedition transect and corresponding to a subset of the data presented in (Karlusich JJP, et al. 2020), were selected for this study since these stations were the only ones for which : i) diazotrophs were present in surface waters and ii) metagenomes samples from both surface $(5 \mathrm{~m})$ and mesopelagic waters were collected and sequenced (200-1000 m ; Supplementary Table S2). Briefly, the plankton were separated into discrete organismal size fractions using a serial filtration system ${ }^{75}$ corresponding to picoplankton size $(0.2-3$ $\mu \mathrm{m})$, nanoplankton (0.8-3 $\mu \mathrm{m}$ or $0.8-5 \mu \mathrm{m})$ and a 'bulk' size fraction corresponding to the fraction $>0.8$ $\mu \mathrm{m}$ or $>3 \mu \mathrm{m}$. Metagenomes were sequenced as Illumina overlapping paired reads of 100-108 bp, which were merged and trimmed based on quality, resulting in $100-215$ bp fragments ${ }^{76}$. Metagenomic reads were recruited against a database of 9 representative genomes of cyanobacterial diazotrophs (Table S1) using BLASTN (v2.9.0; (Altschul et al., 1990 ${ }^{77}$ ) with default parameters but limiting the results to one target sequence (--max_target_seqs 1 ) and keeping only results with an E-value below 1 e-30 (-evalue 1e-30) and with a query coverage of, at least, $90 \%$ of the read length (-qcov_hsp_perc 90). Following the criteria proposed by Caro-Quintero \& Konstantinidis ${ }^{78}$ for metagenome-based prokaryotic genome classification, reads mapping to diazotroph genomes with a percentage of nucleotide identity equal or greater than $95 \%$ were taxonomically assigned to each diazotroph genome according to their best hit, except reads that mapped to the ribosomal operon of any of the diazotroph genomes that were filtered out. The number of reads recruited by each diazotroph genome was normalized to the sequencing depth of each sample (Table S2). For Fig. 8, only samples for which genome coverage was higher than $1 \%$ were taken into account for each organism. 
Table 1. Particulate nitrogen (PON) export fluxes at stations S05M and S10M at $170 \mathrm{~m}, 270 \mathrm{~m}$ and $1000 \mathrm{~m}$, and contribution of diazotrophs to total PON export.

\begin{tabular}{|c|c|c|c|c|}
\hline & Station/Depth (m) & $170 \mathrm{~m}$ & $270 m$ & $1000 \mathrm{~m}$ \\
\hline PON export flux ( $\mathrm{mg} \mathrm{N} \mathrm{m}^{-2} \mathrm{~d}^{-1}$ ) & & $4.9 \pm 0.6$ & $6.1 \pm 1.2$ & $1.6 \pm 0.2$ \\
\hline Diazotroph-PON ( $\mathrm{mg} \mathrm{N} \mathrm{m}^{-2} \mathrm{~d}^{-1}$ ) & S05M & 0.9 & 2.3 & 1.6 \\
\hline Contribution diazotrophs (\%) & & 18 & 38 & 100 \\
\hline PON export flux ( $\mathrm{mg} \mathrm{N} \mathrm{m}^{-2} \mathrm{~d}^{-1}$ ) & & $13.4 \pm 1.3$ & $9.7 \pm 0.6$ & $5.2 \pm 0.1$ \\
\hline Diazotroph-PON ( $\mathrm{mg} \mathrm{N} \mathrm{m}^{-2} \mathrm{~d}^{-1}$ ) & S10M & 1.2 & 1.2 & 2.7 \\
\hline Contribution diazotrophs (\%) & & 9 & 12 & 52 \\
\hline
\end{tabular}

551

552

553

554

555

556

557

558

559

560

561

562

563

564

565

566

567

568

569

570

571

572

573

574

575

576

577

578

579

580

581

582

583

584

585

586

587
Figure 1. a. Surface chlorophyll MODIS composite averaged over the time period corresponding to the TONGA cruise (1 November-6 December 2019) at a resolution of $4 \mathrm{~km}$. Black triangles correspond to stations where surface-tethered drifting sediment traps were deployed (170 m, $270 \mathrm{~m}, 1000 \mathrm{~m})$. Grey dots correspond to stations where Marine Snow Catcher (MSC) casts were performed at three depths (see Methods), and white dots to MSC casts performed at one depth $(200 \mathrm{~m})$. Black circles correspond to stations where the bottlenet profiles were performed between $2000 \mathrm{~m}$ and $200 \mathrm{~m}$. b. Abundances of the five nifH phylotypes (Log10 nifH gene copies $\mathrm{L}^{-1}$ ) studied during the cruise over the transect (averages over the photic layer, $\sim 0-130 \mathrm{~m}$ ).

Figure 2. Relative abundance of diazotroph genera on sediment trap samples. The dendrogram corresponds to the clustering of samples generated by Bray-Curtis similarity. The legend indicates the nifH genus affiliation.

Figure 3. a. Export flux (nifH gene copies $\mathrm{m}^{-2} \mathrm{~d}^{-1}$ ) of the five diazotroph groups targeted by qPCR (UCYN-A1 symbiosis, UCYN-B, UCYN-C, Trichodesmium and Gamma-A) in sediment trap samples at $170 \mathrm{~m}, 270 \mathrm{~m}$ and $1000 \mathrm{~m}$ at stations S05M and b. at S10M. Error bars represent strandard deviations from triplicate aliquote analyzed in duplicates. c. Export turnover rates $\left(d^{-1}\right)$ of the same diazotroph groups (average of the three depths and the two stations for each group).

Figure 4. Microscopy images showing examples of phycoerythrin-containing UCYN-like cells and Trichodesmium in sediment trap samples collected at $170 \mathrm{~m}, 270 \mathrm{~m}$, and $1000 \mathrm{~m}$ at stations S05M and S10M. a-f. Images taken by epifluorescence microscopy (green excitation 510-560 nm, scale bar: $50 \mu \mathrm{m})$. k-I. Image taken by scanning electron microscopy (SEM).

Figure 5. Relative abundance of diazotroph genera from marine snow catcher samples. The dendrogram corresponds to the clustering of samples generated by Bray-Curtis similarity. The legend indicates the nifH genus affiliation.

Figure 6. a-e. Quantification of the five diazotroph groups targeted by GPCR in Marine Snw catcher samples: UCYN-A1 symbiosis: Trichodesmium, UCYN-B, UCYN-C, and Gamma-A in the suspended (dark color), slow sinking (medium color) and fast sinking (light color) pools of the MSC samples across the transect (left $Y$ axis, nifH gene copies $L^{-1}$ ). Dots represent the integrated pool of each phylotype (right $Y$ axix, nifH gene copies $\left.\mathrm{m}^{-2}\right)$ in the photic $(\sim 0-130 \mathrm{~m})$ layer. f. Percentage of sinking versus non-sinking diazotrophs for each group. 
601

602

603

604

605

606

607

608

609

610

611

612

613

614

615

616

617

618

619

620

621

622

623

624

625

626

627

628

629

630

631

632

633

634

635

636

637

638

639

640

641

642

Figure 7. Abundance (nifH gene copies $\mathrm{m}^{-2}$ ) of the five diazotroph groups targeted by qPCR (UCYNA1 symbiosis, Trichodesmium, UCYN-B, UCYN-C, and Gamma-A) in the bottle-net samples across the transect, representing an integrated sample from $200 \mathrm{~m}$ to $2000 \mathrm{~m}$.

Figure 8. Distribution of diazotrophic cyanobacteria in surface and mesopelagic waters during the Tara Oceans expedition. A. Geographical location of the Tara oceans stations used in this study. Only stations in which diazotrophic cyanobacteria were present in surface and metagenomes were available both from surface and mesopelagic waters were selected. B. Abundance of metagenomic reads recruited against different diazotrophic cyanobacteria genomes in surface and mesopelagic samples. See Table S2 for the complete dataset. Note that to better visualize the data, read abundance was expressed as number of reads per 100,000 total reads for surface samples (left axis) and per 1,000,000 total reads for mesopelagic samples (right axis).

\section{Acknowledgements}

This research is a contribution of the TONGA project (Shallow hydroThermal sOurces of trace elemeNts: potential impacts on biological productivity and the bioloGicAl carbon pump; TONGA cruise DOI: $10.17600 / 18000884$ ) funded by the Agence Nationale de la Recherche (grant TONGA ANR-18CE01-0016 and grant CINNAMON ANR-17-CE2-0014-01), the LEFE-CyBER program (CNRS-INSU), the A-Midex foundation, the Institut de Recherche pour le Développement (IRD). F.M.C-C. and L.G acknowledge funding from the European Union's Horizon 2020 research programme under the Marie Sklodowska-Curie grant agreement No. 749380 (UCYN2PLAST). The authors warmly thank the crew of the R/V L'Atalante for outstanding shipboard operations. Nagib Bhairy is warmly thanked for his efficient help with MSC deployment and clean CTD rosette management and Vincent Taillandier is tanked for CTD data processing.

\section{Author contributions}

SB designed the experiments and SB, MB and IBF carried them out at sea, with advice from FLM; SB, MB, MC, OG, AT, DS analyzed the samples; FMCC and LG analyzed the Tara Oceans metagenomes. SB analyzed the data with the help of MB for the sequencing data. SB prepared the manuscript with contributions of all co-authors.

\section{References}

1. Moore CM, et al. Processes and patterns of oceanic nutrient limitation. Nature Geoscience 6, 701-710 (2013).

2. Gruber N. The marine nitrogen cycle: overview and challenges. In: Nitrogen in the marine environment) (2008).

3. Eppley RW, Peterson BJ. The flux of particulate organic matter to the deep ocean and its relation to planktonic new production. Nature 282, 677-680 (1979).

4. Mulholland MR. The fate of nitrogen fixed by diazotrophs in the ocean. Biogeosciences 4, 37-51 (2007).

5. Adam B, et al. N2-fixation, ammonium release and N-transfer to the microbial and classical food web within a plankton community. The ISME journal 10, 450-459 (2016).

6. Bonnet S, et al. Diazotroph derived nitrogen supports diatom growth in the South West Pacific: A quantitative study using nanoSIMS. Limnology and Oceanography 61, 1549-1562 (2016).

7. Robinson C, et al. Mesopelagic zone ecology and biogeochemistry - a synthesis. Deep-Sea Research Part Ii-Topical Studies in Oceanography 57, 1504-1518 (2010). 
643

644

645

646

647

648

649

650

651

652

653

654

655

656

657

658

659

660

661

662

663

664

665

666

667

668

669

670

671

672

673

674

675

676

677

678

679

680

681

682

683

684

685

686

687

688

689

690

691

8. Richardson TL, Jackson GA. Small phytoplankton and carbon export from the surface ocean. Science 315, 838-840 (2007).

9. Subramaniam A, et al. Amazon River enhances diazotrophy and carbon sequestration in the tropical North Atlantic Ocean. Proceedings of the National Academy of Sciences 105, 10460-10465 (2008).

10. White AE, et al. Nitrogen fixation in the Gulf of California and the Eastern Tropical North Pacific. Progess in Oceanography 109, 1-17 (2012).

11. Karl DM, Church MJ, Dore JE, Letelier R, Mahaffey C. Predictable and efficient carbon sequestration in the North Pacific Ocean supported by symbiotic nitrogen fixation. Proceedings of the National Academy of Sciences 109, 1842-1849 (2012).

12. Luo YW, et al. Database of diazotrophs in global ocean: abundances, biomass and nitrogen fixation rates. Earth System Science Data 5, 47-106 (2012).

13. Sharek RM, Tupas LM, Karl DM. Diatom fluxes to the deep sea in the oligotrophic North Pacific gyre at Station ALOHA. Marine and Ecological Progress Series 82, 5567 (1999).

14. Walsby AE. The gas vesicles and buoyancy of Trichodesmium. Marine Pelagic Cyanobacteria: Trichodesmium and other Diazotrophs, 141-161 (1992).

15. Chavez FP, Ryan J, Lluch-Cota SE, Niquen M. From anchovies to sardines and back: Multidecadal change in the Pacific Ocean. Science 299, 217-221 (2003).

16. Pabortsava $\mathrm{K}$, et al. Carbon sequestration in the deep Atlantic enhanced by Saharan dust. Nature Geoscience 10, 189-U141 (2017).

17. Guidi L, et al. Does eddy-eddy interaction control surface phytoplankton distribution and carbon export in the North PacificSubtropical Gyre? Journal of Geophysical Research 117, (2012).

18. Caffin M, et al. N2 fixation as a dominant new $\mathrm{N}$ source in the western tropical South Pacific Ocean (OUTPACE cruise). Biogeosciences 15, 2565-2585 (2018).

19. Agusti S, et al. Ubiquitous healthy diatoms in the deep sea confirm deep carbon injection by the biological pump. Nat Commun 6, 7608 (2015).

20. Berthelot $\mathrm{H}$, et al. Dinitrogen fixation and dissolved organic nitrogen fueled primary production and particulate export during the VAHINE mesocosm experiment (New Caledonia lagoon). Biogeosciences 12, 4099-4112 (2015).

21. Bonnet S, et al. Dynamics of N2 fixation and fate of diazotroph-derived nitrogen in a low nutrient low chlorophyll ecosystem: results from the VAHINE mesocosm experiment (New Caledonia) Biogeosciences 13, 2653-2673 (2016). 
692 22. Farnelid H, et al. Diverse diazotrophs are present on sinking particles in the North

693

694

695

696

697

698

699

700

701

702

703

704

705

706

707

708

709

710

711

712

713

714

715

716

717

718

719

720

721

722

723

724

725

726

727

728

729

730

731

732

733

734

735

736

737

738

739

740

741

Pacific Subtropical Gyre. Isme Journal 13, 170-182 (2019).

23. Moran XAG, Lopez-Urrutia A, Calvo-Diaz A, Li WKW. Increasing importance of small phytoplankton in a warmer ocean. Global Change Biology 16, 1137-1144 (2010).

24. Polovina JJ, Howell EA, Abecassis M. Ocean's least productive waters are expanding. Geophysical Research Letters 35, (2008).

25. Karl D, Michaels A, Bergman B, Capone DG, Carpenter EJ, Letelier R. Dinitrogen fixation in the world's oceans. Biogeochemistry 57/58, 47-98 (2002).

26. Bonnet S, Caffin M, Berthelot H, Moutin T. Hot spot of $\mathrm{N} 2$ fixation in the western tropical South Pacific pleads for a spatial decoupling between N2 fixation and denitrification. Proceedings of the National Academy of Sciences 114, E2800-E2801 (2017).

27. de Boyer Montégut C, Madec G, Fischer AS, Lazar A, Iudicone D. Mixed layer depth over the global ocean: An examination of profile data and a profile-based climatology. Journal of Geophysical Research: Oceans 109, (2004).

28. Hewson I, Moisander PH, Morrison AE, Zehr JP. Diazotrophic bacterioplankton in a coral reef lagoon: phylogeny, diel nitrogenase expression and response to phosphate enrichment. Isme Journal 1, 78-91 (2007).

29. Turk-Kubo KA, Frank IE, Hogan ME, Desnues A, Bonnet S, Zehr JP. Diazotroph community succession during the VAHINE mesocosms experiment (New Caledonia Lagoon). Biogeosciences 12, 7435-7452 (2015).

30. Riley JS, Sanders R, Marsay C, Le Moigne FAC, Achterberg EP, Poulton AJ. The relative contribution of fast and slow sinking particles to ocean carbon export. Global Biogeochemical Cycles 26, (2012).

31. Cornejo-Castillo FM, Zehr JP. Intriguing size distribution of the uncultured and globally widespread marine non-cyanobacterial diazotroph Gamma-A. The ISME journal 15, 124-128 (2021).

32. Karlusich JJP, et al. Global distribution patterns of marine nitrogen-fixers by imaging and molecular methods. BioRxiv, (2020).

33. Salazar G, et al. Gene Expression Changes and Community Turnover Differentially Shape the Global Ocean Metatranscriptome. Cell 179, 1068-1083 e1021 (2019).

34. Durkin CA, Van Mooy BAS, Dyhrman ST, Buesseler KO. Sinking phytoplankton associated with carbon flux in the Atlantic Ocean. Limnology and Oceanography 61, 1172-1187 (2016).

35. Cornejo-Castillo FM. Diversity, ecology and evolution of marine diazotrophic microorganisms.). Polytechnic Univ. of Catalonia (UPC) (2017). 
36. Harding K, Turk-Kubo KA, Sipler RE, Mills MM, Bronk DA, Zehr JP. Symbiotic unicellular cyanobacteria fix nitrogen in the Arctic Ocean. Proceedings of the National Academy of Sciences of the United States of America 115, 13371-13375 (2018).

37. Shiozaki T, et al. Diazotroph community structure and the role of nitrogen fixation in the nitrogen cycle in the Chukchi Sea (western Arctic Ocean). Limnology and Oceanography 63, 2191-2205 (2018).

38. Thompson AW, et al. Unicellular Cyanobacterium Symbiotic with a Single-Celled Eukaryotic Alga. Science 337, 1546-1550 (2012).

39. Poff KE, Leu AO, Eppley JM, Karl DM, DeLong EF. Microbial dynamics of elevated carbon flux in the open ocean's abyss. Proceedings of the National Academy of Sciences of the United States of America 118, (2021).

40. Sohm JA, Edwards BR, Wilson BG, Webb EA. Constitutive Extracellular Polysaccharide (EPS) Production by Specific Isolates of Crocosphaera watsonii. Frontiers in microbiology 2, 229 (2011).

41. Berman-Frank I, Dubinsky Z. Balanced growth in aquatic plants: Myth or reality? Phytoplankton use the imbalance between carbon assimilation and biomass production to their strategic advantage. Bioscience 49, 29-37 (1999).

42. Walsby AE. The properties and buoyancy-providing role of gas vacuoles in Trichodesmium Ehrenberg. European Journal of Phycology 13, 103-116 (1978).

43. Berman-Frank I, Bidle KD, Haramaty L, Falkowski PG. The demise of the marine cyanobacterium, Trichodemsium spp., via an autocatalyzed cell death pathway. Limnology and Oceanography 49, 997-1005 (2004).

44. Berman-Frank I, Rosenberg G, Levitan O, Haramaty L, X. M. Coupling between autocatalytic cell death and transparent exopolymeric particle production in the marine cyanobacterium Trichodesmium. Environmental microbiology 9, 1415-1422 (2007).

45. Bar-Zeev E, Avishay I, Bidle KD, Berman-Frank I. Programmed cell death in the marine cyanobacterium Trichodesmium mediates carbon and nitrogen export. ISME Journal 7, 2340-2348 (2013).

46. Buesseler KO. The decoupling of production and particulate export in the surface ocean. Global Biogeochemical Cycles 12, 297-310 (1998).

47. Buesseler KO, Boyd PW, Black EE, Siegel DA. Metrics that matter for assessing the ocean biological carbon pump. Proceedings of the National Academy of Sciences of the United States of America 117, 9679-9687 (2020).

48. Benavides M, et al. Staying alive: fast sinking Trichodesmium remains active in the twilight zone. (In prep.). 
802

803

804

805

806

807

808

809

810

811

812

813

814

815

816

817

818

819

820

821

822

823

824

825

826

827

828

829

830

831

832

833

834

835

836

837

838

839

840

49. Ababou FE, Le Moigne F, Bonnet S. Mechanistic understanding of diazotroph aggregation: a rolling tank aproach. Targetted journal: Limnology and Oceanography, (In prep.).

50. Berthelot H, Bonnet S, Camps M, Grosso O, Moutin T. Assessment of the dinitrogen released as ammonium and dissolved organic nitrogen by unicellular and filamentous marine diazotrophic cyanobacteria grown in culture. Frontiers in Marine Science 2, (2015).

51. Glibert PM, Bronk D. Release of dissolved organic nitrogen by marine diazotrophic cyanobacteria, Trichodesmium spp. Applied and Environmental Microbiology 60, 3996-4000 (1994).

52. Mulholland MR, Bernhardt PW, Heil CA, Bronk DA, O'Neil JM. Nitrogen fixation and regeneration in the Gulf of Mexico. Limnology and Oceanography 51, 176-177 (2006).

53. Capone DG, et al. An extensive bloom of the $\mathrm{N}_{2}$-fixing cyanobacterium, Trichodesmiumn erythraeum, in the Central Arabian Sea. Marine Ecology Progress Series 172, 281-292 (1998).

54. Steinberg DK, Landry MR. Zooplankton and the Ocean Carbon Cycle. Annu Rev Mar Sci 9, 413-444 (2017).

55. Engel A, Wagner H, Le Moigne FAC, Wilson ST. Particle export fluxes to the oxygen minimum zone of the eastern tropical North Atlantic. Biogeosciences 14, 1825-1838 (2017).

56. Berthelot H, Benavides M, Moisander PH, Grosso O, Bonnet S. High nitrogen fixation rates in the particulate and dissolved pools in the Western Tropical Pacific (Solomon and Bismarck Seas). Geophysical Research Letters, (2017).

57. Bonnet $\mathrm{S}$, et al. In-depth characterization of diazotroph activity across the western tropical South Pacific hotspot of N-2 fixation (OUTPACE cruise). Biogeosciences 15, 4215-4232 (2018).

58. Conte MH, Ralph N, Ross EH. Seasonal and interannual variability in deep ocean particle fluxes at the Oceanic Flux Program (OFP)/Bermuda Atlantic Time Series (BATS) site in the western Sargasso Sea near Bermuda. Deep-Sea Research Part IiTopical Studies in Oceanography 48, 1471-1505 (2001).

59. Ras J, Claustre H, Uitz J. Spatial variability of phytoplankton pigment distributions in the Subtropical South Pacific Ocean: comparison between in situ and predicted data. Biogeosciences 5, 353-369 (2008).

60. Lampitt RS, Wishner KF, Turley CM, Angel MV. Marine Snow Studies in the Northeast Atlantic-Ocean - Distribution, Composition and Role as a Food Source for Migrating Plankton. Marine Biology 116, 689-702 (1993). 
841 61. Passow U, Alldredge AL. A dye-binding assay for the spectrophotometric

842

843

844

845

846

847

848

849

850

851

852

853

854

855

856

857

858

859

860

861

862

863

864

865

866

867

868

869

870

871

872

873

874

875

876

877

878

879

880

881

882

883

884

885

886

887

888

889 measurement of transparent exopolymer particles (TEP). Limnology and Oceanography 40, 1326-1335 (1995).

62. Moisander PH, Beinart RA, Voss M, Zehr JP. Diversity and abundance of diazotrophic microorganisms in the South China Sea during intermonsoon. Isme Journal 2, 954-967 (2008).

63. Zehr JP, Turner PJ. Nitrogen fixation: Nitrogenase genes and gene expression. In: Methods in Marine Microbiology (ed Paul JH). Academic Press (2001).

64. Callahan BJ, McMurdie PJ, Rosen MJ, Han AW, Johnson AJA, Holmes SP. DADA2: High-resolution sample inference from Illumina amplicon data. Nat Methods 13, 581$+(2016)$.

65. Church MJ, Jenkins BD, Karl DM, Zehr JP. Vertical distributions of nitrogen-fixing phylotypes at Stn ALOHA in the oligotrophic North Pacific Ocean. Aquatic Microbial Ecology 38, 3-14 (2005).

66. Moisander AM, Beinart A, Voss M, Zehr JP. Diversity and abundance of diazotrophs in the South China Sea during intermonsoon. The ISME journal 2, 954-967 (2008).

67. Thompson A, Carter BJ, Turk-Kubo K, Malfatti F, Azam F, Zehr JP. Genetic diversity of the unicellular nitrogen-fixing cyanobacteria UCYN-A and its prymnesiophyte host. Environmental microbiology 16, 3238-3249 (2014).

68. Sun J, Liu D. Geometric models for calculating cell biovolume and surface area for phytoplankton. Journal of Plankton Research 25, 1331-1346 (2003).

69. Verity PG, Robertson CY, Tronzo CR, Andrews MG, Nelson JR, Sieracki ME. Relationships between cell volume and the carbon and nitrogen content of marine photosynthetic nanoplankton. Limnology and Oceanography 37, 1434-1446 (1992).

70. Dekaezemacker J, Bonnet S. Sensitivity of $\mathrm{N}_{2}$ fixation to combined nitrogen forms $\left(\mathrm{NO}_{3}{ }^{-}\right.$and $\left.\mathrm{NH}_{4}{ }^{+}\right)$in two strains of the marine diazotroph Crocosphaera watsonii (Cyanobacteria). Marine Ecology Progress Series 438, 33-46 (2011).

71. Knapp AN, Dekaezemacker J, Bonnet S, Sohm JA, Capone DG. Sensitivity of Trichodesmium erythraeum and Crocosphaera watsonii abundance and $\mathrm{N}_{2}$ fixation rates to varying $\mathrm{NO}_{3}{ }^{-}$and $\mathrm{PO}_{4}{ }^{3-}$ concentrations in batch cultures. Aquatic Microbial Ecology 66, 223-236 (2012).

72. Martinez-Perez C, et al. The small unicellular diazotrophic symbiont, UCYN-A, is a key player in the marine nitrogen cycle. Nature Microbiology 1, 16163 (2016).

73. Rodier M, Le Borgne R. Population and trophic dynamics of Trichodesmium thiebautii in the SE lagoon of New Caledonia. Comparison with T. erythraeum in the SW lagoon. Marine Pollution Bulletin 61, 349-359 (2010). 
890 74. Sargent EC, et al. Evidence for polyploidy in the globally important diazotroph Trichodesmium. FEMS microbiology letters 363, (2016).

892

893

894

895

896

897

898

899

900

901

902

903

75. Pesant S, et al. Open science resources for the discovery and analysis of Tara Oceans data. Sci Data 2, (2015).

76. Alberti A, et al. Viral to metazoan marine plankton nucleotide sequences from the Tara Oceans expedition. Sci Data 4, (2017).

77. Altschul SF, Gish W, Miller W, Myers EW, Lipman DJ. Basic Local Alignment Search Tool. Journal of molecular biology 215, 403-410 (1990).

78. Caro-Quintero A, Konstantinidis KT. Bacterial species may exist, metagenomics reveal. Environmental microbiology 14, 347-355 (2012).

904

905 

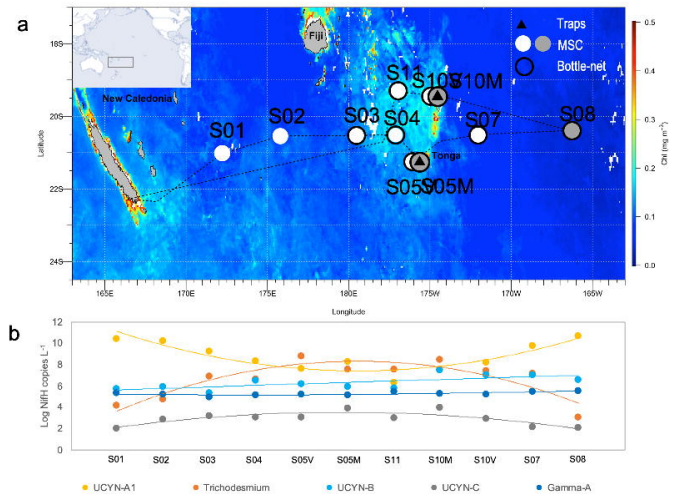


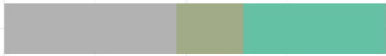

\section{Genus}

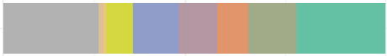

S3ile traps tecom

s10M rapo $370 \mathrm{~m}$

B10M trap $270 \mathrm{~m}$

stok traps tecom
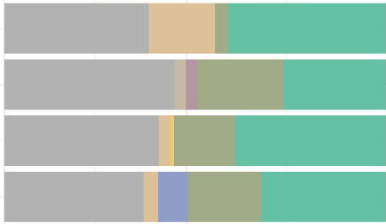

Trichocesmium

Crocosplocen

Cundidulas.

Stenotrophamens:

Azorionsium

Novoconngohism

Carborrucosta

Sufurowim

Netiycoversalts

Xonfobacter

Narinotocter

Varisuorax

Nogibactatium

Arrobacter

Ampritea

Kejognymene

Fichelo

Other 

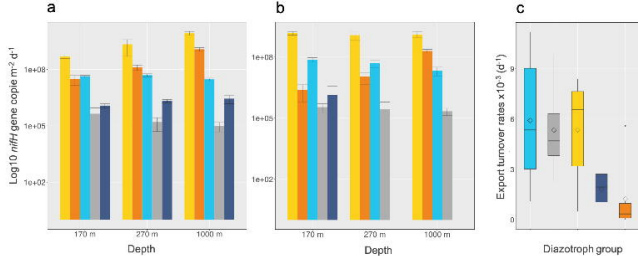

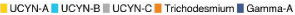


a

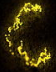

S05M-170 m

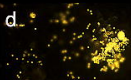

S10M-170 on ma

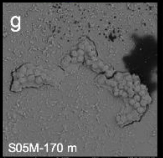

b

\section{S05M-270 m}
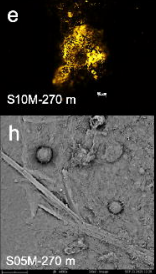

c

S05M-1000 m
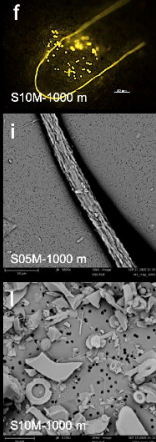
SDi MSC is $200 \mathrm{~m}$
SO1 MSC it $200 \mathrm{~m}$ sol MSE sisp $200 \mathrm{~m}$ 502 1.1SC $\%=200 \mathrm{~m}$ $502 \mathrm{MSE}$. $58-200 \mathrm{~m}$ S02 MSC susp $200 \mathrm{~m}$ sor ber fo $200 \mathrm{~mm}$ $303725 \mathrm{~s}$ ss $200 \mathrm{~m}$ 503 MSC aus $200 \mathrm{~m}$ SDA Mise is $200 \mathrm{~m}$ 504 MSC $15200 \mathrm{~m}$ SOL ITSE SISP $200 \mathrm{~m}$ $505 \mathrm{M}$ iASC $\mathrm{fo} 7000 \mathrm{~m}$ 05 Mnce $1000 \mathrm{~m}$ sosM MASC fs $200 \mathrm{~m}$ SOSM MSC fs $270 \mathrm{~m}$ sow Misc 53 romm SOSM MSE $: 170 \mathrm{~m}$ $505 \mathrm{M}$ - $5 \mathrm{C}=25 \mathrm{mom}$ $50 \mathrm{~m}$. 35 , $00 \mathrm{~m}$ OSN MSC susp $1000 \mathrm{~m}$ SCSM NSC Susp $170 \mathrm{~m}$ SCSN VSC SUIP $200 \mathrm{~m}$

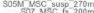
SE7 J ISC \& $200 \mathrm{~m}$ S07 MSC susp $200 \mathrm{~m}$ 508 L $A 5 C$ Is $1000 \mathrm{~m}$ $B D B$ M $119 \mathrm{C}$ f $2000 \mathrm{~m}$ $50 x$ MSE $33=000 m$ $5007 \mathrm{Me}=38=2000 \mathrm{~m}$ 506 Mad $93.2000 \mathrm{~m}$ S08 MSC susp $1000 \mathrm{~m}$ 508 ASC susp $2000 \mathrm{~m}$ $510 \mathrm{M}$ MEC $1000 \mathrm{~m}$ S $10 \mathrm{M}$ MSC $\mathrm{F}_{0}+70 \mathrm{~m}$ $570 \mathrm{M}$ 205 to $200 \mathrm{~m}$ s.on use fs $200 m$ SiTu NSC Ss rooon Stan MSC 33 . $000 \mathrm{~m}$ S1OM MBC is $170 \mathrm{~m}$ S1OM MSC of $200 \mathrm{~m}$ S10M MSC $\$ 5$ ? $270 \mathrm{~m}$ S1CN MSC SuP TOCOD S7CN MSE susp $170 \mathrm{~m}$ STON WSC susp $200 \mathrm{~m}$ STLN MSC EU2 $27 \mathrm{~m}$ 5T MSC $35200 \mathrm{~m}$

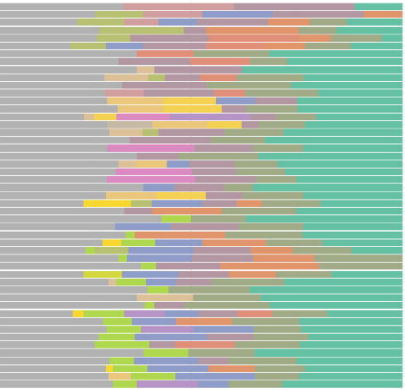

Genus

Trichadesmum

Crocosphaera

Candiciatus

Stenotreptamonas

Azochizobium

Novosphingoblum

Carnoxyoocala

Sufurevern

Mothylavorootilis

Xanthobecter

Marincbacier

variorasex

Mogibacterium

Aroobector

Amphritea

Katagnymene

Richelia

Other 


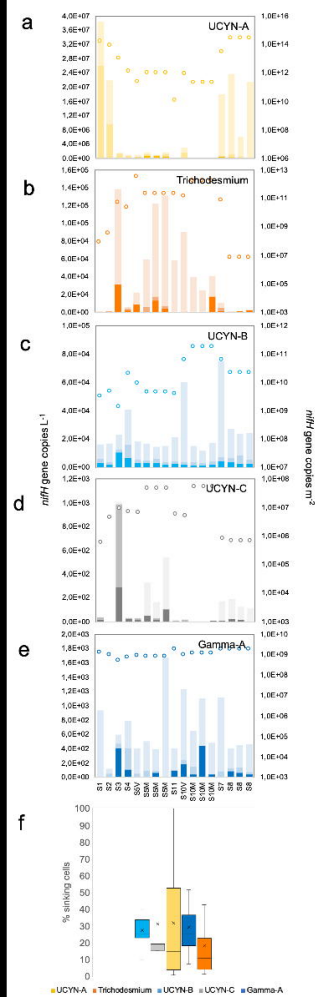




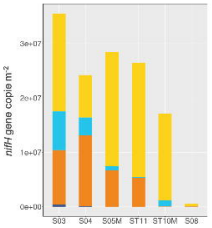

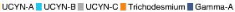


a

b
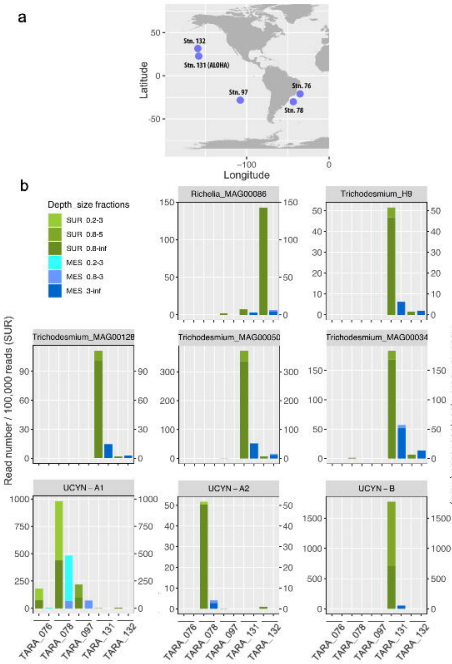

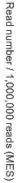

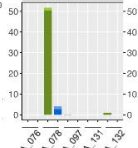

$-7500$

(15)

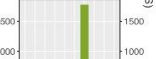

$5^{2} x^{2} a^{3} x^{2} a^{2}$

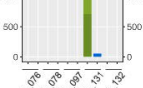

